\title{
A LINGUAGEM DOS QUADRINHOS NO ENSINO MÉDIO - UM CAMINHO PARA ESTUDAR LITERATURA BRASILEIRA
}

\section{ARTIGO ORIGINAL}

LISBOA, Adébio de Jesus Ribeiro ${ }^{1}$

OLIVEIRA, Ivana Esteves Passos de ${ }^{2}$

LISBOA, Adébio de Jesus Ribeiro. OLIVEIRA, Ivana Esteves Passos de. A linguagem dos quadrinhos no Ensino Médio - Um caminho para estudar literatura brasileira. Revista Científica Multidisciplinar Núcleo do Conhecimento. Ano 05, Ed. 07, Vol. 03, pp. 63-80. Julho de 2020. ISSN: 2448-0959, Link de acesso: https://www.nucleodoconhecimento.com.br/educacao/linguagem-dosquadrinhos

\section{RESUMO}

A aplicabilidade da linguagem dos quadrinhos no Ensino Médio como um mecanismo para facilitar a apreensão da literatura brasileira tem sua relevância consolidada no propósito de se evidenciar uma experiência didática inusitada, consubstanciada na promoção do entrelace com a linguagem dos quadrinhos para o estudo de cânones literários, unindo o popular e o clássico na configuração de uma metodologia ativa. Os quadrinhos, ao se constituírem como uma forma de arte sequencial, informam, educam e comunicam instantaneamente e intencionalmente. Esse estudo oportuniza aos estudantes condições mais acessíveis de compreensão leitora, em vista da combinação da linguagem verbal e não verbal, possibilitando análise, interpretação e desenvolvimento da leitura crítica. Trabalhou-se a modalidade de pesquisa

\footnotetext{
${ }^{1}$ Mestre em Ciência Tecnologia e Educação pela Faculdade do Vale do Cricaré; Graduado em Letras-Português pela Universidade Metropolitana de Santos UNIMES.

2 Orientadora. Doutora em Letras.
} 
exploratória, mediante investigação bibliográfica e de pesquisa-ação, o que permitiu a exploração dos quadrinhos como ferramenta metodológica aplicável nas aulas de literatura em turmas do Ensino Médio. O interesse principal com esta abordagem foi o de motivar o estudante a participar do mundo literário, apropriando-se de sua riqueza singular.

Palavras-Chave: Histórias em quadrinhos, quadrinização, literatura, interdisciplinaridade.

\section{INTRODUÇÃO}

Em face às constantes mudanças na sociedade do século $X X I$, sobretudo com o desenvolvimento e aprimoramento das Tecnologias de Informação e Comunicação (TIC), o professor em sala de aula tem procurado conduzir seus procedimentos de ensino-aprendizagem em consonância e em dialogia com os discentes, no intuito de propiciar-lhes uma ampla formação e, para isto, há que levar em consideração suas singularidades, habilidades e práticas autônomas de aprendizagem. Especificamente no contexto da disciplina de Literatura Brasileira, cumpre, à este docente, oportunizar ao aluno a exploração de textos de autores brasileiros de modo prazeroso, levando o estudante à um estado de fruição, despertando-lhe, portanto, o interesse por meio do aprimoramento de suas estratégias de leitura literária.

E, seguindo as premissas de Freire (1997), o ato de ensinar não é meramente transmitir conhecimento, mas gerar possibilidades para sua produção ou sua construção pelos próprios educandos. Dentre os caminhos possíveis, como metodologia a ser aplicada em sala de aula, pensou-se numa composição da oferta de textos literários e textos adaptados para a linguagem de quadrinhos. Há no mercado versões de grandes títulos da literatura brasileira, publicados em quadrinhos. Assim: "o gênero quadrinhos apresenta uma modalidade própria de linguagem. Dois tipos de signos gráficos se conjugam na sua construção: o visual e o linguístico" (LINS, 2008, p. 39), em que o visual está fazendo referência à toda a representação de imagens, expressões (de humor, de alegria, de tristeza, etc.) e o linguístico, porque 
possibilita o uso de gírias, onomatopeias, diferentes formas de expressão de letras, que possuem significados próprios e independentes.

O interesse principal com esta abordagem é motivar o estudante a participar do mundo literário, apropriando-se de sua riqueza singular, sem perder a função pragmática do ensino formal de literatura que tem marcado a história clássica da educação. A literatura possui uma função útil na vida humana que vai além de proporcionar divertimento, é aliviar a tensão provocada pela realidade e levar o ser humano a travar contato com o universo mágico da fantasia e da construção emocional, afetiva. Este é um princípio complexo, porque não somente o estudante é inserido em um formato inovador de aprendizagem, o que sugere a adaptação a um método singular de aprender, e, então, o professor vê-se obrigado a adaptar os seus modos e métodos de ensino, porque a nova estrutura de linguagem está em um nível nem abaixo nem acima do clássico.

Encontra-se em um patamar diferenciado em que deve existir uma interação entre o que se pretende ensinar e o que se espera que o estudante venha a aprender, tornando-se coadjuvante no processo didático da literatura. A linguagem dos quadrinhos é uma forma de aproximar-se de uma construção mais sintetizada de formas de pensamento complexo, o que conduz o pensar a leitura de um clássico em formato de prosa, entretanto, isso demanda uma condição de fruição do pensamento altamente complexa, linearizada e que confronta com as novas perspectivas de ensino e aprendizado mais concatenadas com os tempos presentes. O objetivo que se propõe com esta nova abordagem didática para o ensino de literatura se dá em meio à estudos que apresentam novas performances dos sujeitos da aprendizagem, na perspectiva dialógica de Bakhtin, em que o foco passa da obra para a possibilidade de interação entre leitor e o objeto de sua leitura/análise.

Os estudos até agora apresentados têm mostrado que não há perda nos ganhos objetivos de formação da personalidade leitora dos estudantes, porque como estão na potencialidade de análises subjetivas elaboram tertúlias pedagógicas em que a apreensão do saber alcançado é somada ao que se partilha, mediada pela ação didática dialógica proporcionada pelo professor. A leitura, realizada no formato de 
quadrinhos, permite, ao leitor, um espaço maior de flexibilidade quanto ao tempo de vinculação ao seu objetivo de análise, interpretação, compreensão e síntese do que está sendo buscado. Neste processo, o professor não está isento de ter que estar alinhado com o texto clássico em formato de prosa, que se caracteriza como um texto no qual se prolonga em períodos, frases, orações e parágrafos, para que possa, dentro dos limites da formação didática proposta, inferir nas análises dos estudantes, ampliando as formas de compreender a literatura, aproximando-se da mesma.

\section{SOBRE O ENSINO DE LITERATURA CLÁSSICA BRASILEIRA}

O ensino de literatura, desde os primórdios, sempre representou um problema a ser solucionado e que se mostra como uma questão de difícil solução. Isso se deve a presença de algumas questões, como, por exemplo: como se pode ensinar algo que não se pode tocar, a não ser pela sensibilidade e pelo sentimento de compreensão do que foi interpretado a partir da escrita de alguém que não encontra-se mais presente para dizer o que significa suas palavras e expressões? Como exemplo clássico, tomemos a obra de Machado de Assis (1839-1908), Dom Casmurro, em que ele relata sobre a estética de Capitu, que possuía olhos de ressaca e é exatamente neste ponto que se pode deter em meio a uma terrível complicação interpretativa, porque a que tipo de ressaca, refere-se o gênio? À ressaca de uma noite de embriaguez ou à ressaca intrépida do mar?

E a situação não se resolve com nenhuma facilidade, porque ao mesmo tempo em que coloca uma vivacidade voraz no olhar de sua personagem mais enigmática, coloca uma nuvem de mistério em torno do mesmo que faz o leitor perder-se entre um e outro ponto de análise, interpretação e síntese, sem saber o que pensar, de fato. Após esta breve explanação, eis que já se pode aproximar-se do objeto-alvo desta investigação, que é a quadrinização das obras literárias canônicas e já se traça a primeira pergunta-problema, que guiará toda a discussão: Qual expressão estética, artística, visual, semântica, filológica será conferida ao texto a ser adaptado aos quadrinhos? Esta pergunta surge no campo do provável, porque ao criar uma estrutura imagética para um determinado objeto, o artista confere-lhe um tipo de visual 
que pode não ser compatível com aquilo que o autor [do texto original] pensava no exato instante de sua elaboração.

Assim que a expressão de detalhes surreais, de caracteres altamente subjetivos são postos aos leitores como uma verdade finita, pronta e acabada, restringindo o campo da imaginação e da ampla discussão sobre tais elementos e sua condição de livre interpretação, tem-se um problema. O processo de quadrinização de clássicos da literatura brasileira deve ser entendido como uma metodologia ativa que tem como objetivo geral a aproximação do leitor ao seu objeto de interesse, este que é transformado em uma linguagem mais acessível e mais dinâmica, sob vários aspectos psicológicos, visando atender à uma gama selecionada e tratada a partir da óptica da Sociologia, o que produz, como resultado direto, um entendimento mais flexível daquilo para o que se colocaria uma barreira natural, impedindo a construção de pensamentos mais finos e mais profundos em torno do entendimento natural da obra.

Neste sentido, a quadrinização não pode ser vista como um fim em si mesma; um meio por meio do qual se torna possível atingir um fim, sem perder a essência do trabalho original e mesmo as características filológicas inerentes à ele. Não será possível atingir tal condição, porque toda adaptação acarreta em perdas diretas sobre o material original que, a cada manipulação, vai sendo distorcido nos formatos possíveis de entendimento, o que aponta para uma necessidade mais ampla, peremptória, que é o nível de formação e de conhecimento literário do professor para que este possa ajustar qualquer [possível] falha no processo de adaptação que se acarrete em uma dificuldade de aproximação do leitor-estudante ao sentido semântico do texto original, compreendendo que, neste processo, trabalha-se com uma perspectiva da didática e da dialética.

Logo, os objetivos dizem respeito, respectivamente, aos processos formais, pragmáticos e sistemáticos de ensino e de aprendizagem. Está-se trabalhando com a hipótese de que ao adaptar os textos literários canônicos aos quadrinhos tal ação poderá proporcionar uma maior aproximação dos estudantes com a leitura, despertando-Ihes a paixão e o interesse. Isto se mostra bastante possível, porque como defende Oliveira (2008): 
Arte narrativa por natureza, o quadrinho traz em si grande potencial comunicativo, apresentando uma união própria entre as linguagens verbal e não-verbal. Com a literatura, arte que também trabalha com a narratividade, o quadrinho tem estabelecido uma ampla interação, em que as linguagens e enredos se interseccionam (OLIVEIRA, 2008, p. 10).

Esta formação de novas seções de linguagens multidimensionais, onde se mesclam, em especial, a verbal e a visual, promove uma condição inteiramente nova para que o estudante possa tomar esta primeira impressão como um ponto de partida para o desenvolvimento de uma intelectualidade e uma cognição maduras e autônomas sobre a obra estudada, não estando vinculadas à sua capacidade de leitura imagética do mundo, pois, ao mesmo tempo, pode ser positivo e limitante uma leitura a partir de seu mundo interno para o mundo externo, podendo ocorrer o contrário, porque uma visão de mundo e dos personagens já está posta ali, o que não gera aproximação, mas sim distanciamento desse leitor em potencial.

Neste ínterim, o professor deve valer de sua práxis para fazer as interferências mínimas necessárias, orientando e demarcando um espaço em que os estudantes devem explorar para além do que está representado, porque a literatura é uma expressão singular de um mundo particular, portanto, a interpretação do texto e não a leitura é o que interessa, de fato, no ensino da mesma; é o que ela traz de mais essencial da história, da política, do ser em si e para si e não se pode perder de vista toda esta condição auferida pela leitura dos clássicos na formação da personalidade acadêmica do estudante. Neste sentido, Oliveira (2008, p. 10), argumenta que "ambos [literatura clássica e quadrinhos] apresentam recursos que, se bem aproveitados, podem enriquecer e possibilitar diferentes formas de comunicação, permitindo novos 'olhares' sobre a sociedade e a existência humana”.

Surge, assim, o desafio que cabe ao docente, que é o de explorar as condições sobre como aproveitar, ao máximo, as oportunidades apresentadas por ambos os elementos e possibilitar, ao estudante, a realização de uma comparação analítica e se sua resposta for positiva ou negativa a cada uma das partes, isto cabe um processo de análise e compreensão, não podendo creditar juízos de valor ao que se alcança como resposta, partindo do entendimento científico que a resposta auferida pelo objeto trata- 
se de uma variável dependente, ou seja, a ela deve ser conferida toda uma gama de interpretação, sempre que possível, retornando ao objeto, a fim de saber o que está a dizer ou a referir com sua expressão, resposta, colocação, escolha objetal.

A postura do professor, ao levar a efeito sua práxis, deve ser compreendida em sua extensão mais ampla, que é a de que se trata de uma relação dialética de reciprocidade e simultaneidade entre a teoria e a prática, ou seja, não está em discussão a qualidade ou a respeitabilidade da adaptação, porque adulterações contextuais há de haver, sendo inevitável tal ocorrência, porque além de ter-se a questão da ambientação, há ainda o público-alvo a que foi pensada tal ação; se para crianças, se para adolescentes, se para jovens. A cor que se utiliza para adaptar também vai interferir na produção do imaginário do leitor, porque os contos de fadas, por exemplo, são da Europa, fria, cinzenta, dias escuros, noites densas, céu nem tão azul assim, por questões de condições climáticas ou ainda se pensar em $O$ morro dos ventos uivantes[3], de Emily Brontë (1818-1848), em que os personagens são tuberculosos, logo, são magros, caquéticos, pálidos, ausentes deles qualquer traço de beleza estética e a região onde se passa o romance é cercada por pântanos e charnecas, lúgubre e sempre coberta de neblina.

Amarilha (2006) destaca outro ponto marcante no processo de adaptação dos textos canônicos aos formatos de quadrinhos, que é a intertextualidade, havendo uma gama de elementos comunicativos, como a questão textual, em si, a percepção visual sobre o objeto e a produção de imagens em confronto com as que são apresentadas pelo roteirista. Segundo esta autora, "um aspecto que participa de forma sutil, mas definidora na intertextualidade é o ritmo da narrativa. O desenvolvimento das ações ganha extrema agilidade nos quadrinhos como recurso que dá mobilidade aos personagens e leveza às situações" (AMARILHA, 2006, p. 9). O risco que se corre, com toda esta condição de mobilidade e leveza, é o de o estudante acomodar-se à este formato de texto como sendo o último refúgio de aprendizagem para a literatura e o professor, também, assim entender, por vezes picado pela mosca azul[4] da inclusão de grupos marginalizados aos processos mais eletuários de métodos de ensinos. 
O processo segue um padrão em que o docente deve criar uma metodologia capaz de atender aos anelos da didática e não aos anseios particulares de quem esteja a ensinar ou que esteja a aprender.

\section{HQ's NA SALA DE AULA}

Trabalhar literatura em sala de aula continua sendo a mais complexa ação metodológica, porque parte do pressuposto de que aquele que aprende não será capaz de compreender, caso não leia a(s) obra(s) citada(s) e o professor não ensina caso seu aluno não realize a leitura do que foi indicado e ainda debruça-se sobre os pormenores, realizando uma busca muito mais ampla sobre os elementos que cercam o texto e seu autor. Partindo da realidade de mundo do leitor, chega-se, no máximo, a lugar algum, ao famoso mundo da utopia, que, em muito pouco tempo, transformase em uma distopia com a conivência de todos e o entendimento de que estão formando figuras geniais. Nisto, tem-se que, ao quadrinizar obras clássicas literárias, busca-se novas formas metodológicas para se ensinar literatura, visando a aproximação do leitor com o seu objeto de estudo.

Pensado de modo isolado, tem-se um maior distanciamento do trabalho de ensinoaprendizagem, porque cria novas estruturas que não se fazem próximas ao avanço do processo pragmático elaborado didaticamente. Lima (2012) é bastante contundente ao afirmar que o ingresso da Literatura no mundo dos quadrinhos é uma situação recente e inovadora, sendo vista com ressalvas pelos professores que, em termos de literatura clássica, são sempre tradicionais e resistentes à qualquer tipo de inovação. Este é o motivo para que aqui estes textos sejam designados como canônicos[5]. Sobre existe toda uma ordenamento [quase] místico de veneração sobre as obras dos autores clássicos e qualquer manipulação das mesmas fora dos preceitos autorizados pelos sacerdotes da Filologia e da Linguística poderia ser considerada como uma blasfêmia, um ato de vilipêndio contra o pensamento do autor e consequentemente, com sua criação.

Assim, o professor é o primeiro objeto a ser trabalhado psicologicamente quando se pensa em colocar à sua disposição a possibilidade de levar a efeito o ensino de 
literatura clássica utilizando a adaptação quadrinística em sala de aula. Há que derrubar o tabu de que esteja subvalorizando a obra literária, a própria literatura e a arte de ensinar, o que culminaria no entendimento de uma sub aprendizagem. Isso ocorre porque: "até décadas passadas as HQ's eram vistas pelos educadores como uma subliteratura, sem muito caráter instrutivo, ou seja, só era considerada unicamente como uma forma de passatempo" (LIMA, 2012, p. 2). Regina Dalcastagnè comenta:

As histórias em quadrinhos que, até bem pouco tempo atrás, só entravam de contrabando nas mochilas escolares, vêm adquirindo um novo status no Brasil. A tradução e a publicação de álbuns cada vez mais sofisticados, a abertura de espaços próprios para os quadrinhos nas grandes livrarias, as resenhas em jornais e revistas, a participação de quadrinistas em feiras literárias, em programas de entrevistas e em eventos acadêmicos legitima, de algum modo, uma produção que sofria o duplo preconceito de ser ao mesmo tempo, "literatura de massa" e "destinada a crianças e jovens" - o que servia, em última instância, para desqualificar uma expressão artística a partir da desqualificação (etária e de classe) de seus consumidores. [...] Com a ampliação da oferta e, mais importante, das possibilidades de expressão que surgem dos quadrinhos, cresce também a necessidade de uma reflexão mais cuidadosa sobre seus recursos (DALCASTAGNÈ, 2012, p. 7) [Os grifos estão no original].

Dalcastagnè reflete acerca da relevância alcançada pelas HQ's, assim como sobre a expansão de consumidores - indivíduos que aderem à leitura destes, seja de novelas de faroeste, gibis, comics, super-heróis, em muitas das vezes englobando gerações de várias categorias de idades e momentos históricos. O que se percebe é a abrangência de mercado, a despeito da existência, em pleno século XXI, ainda, de preconceito artístico e cultural contra as HQs. As adaptações de textos clássicos para a linguagem de $\mathrm{HQ}$ têm se ampliado, sobretudo de textos clássicos para esse formato de apresentação. E nada disto desvaloriza ou sobrevaloriza uma obra, porque o oposto também tem se dado, em que textos publicados originalmente em formato quadrinístico são transpostos para formatos em prosa ou versos, com ampla aceitação de público, havendo aquelas adaptações que ficam melhores que o original e outras que se mostram fidedignas - e há as que frustram expectativas, variando com a 
capacidade intelecto-cognitivo do leitor/analista e se já tenha travado contato com o material em seu formato primitivo.

A quadrinização é um ato artístico, respeitando todos os preceitos técnicos da arte relacional e o ensino utilizando tal técnica é outra questão bem mais complexa e que possui seus próprios padrões de exigência didática, cabendo, neste sentido, ao professor, o estudo acerca da melhor forma de promover o ensino aos estudantes, visando ao máximo de aprendizagem intelectual formal no campo da literatura vernácula. Há que esclarecer que toda estratégia de ensino, especialmente estas que se vinculam aos trabalhos de línguas vernáculas e literaturas clássicas, já trazem, em seu bojo, uma aura de superioridade, mistério, que tende a assustar os estudantes com a simples menção ao autor que as produziu e, por si só, tal ação cria impossibilidades de aprendizagem e absorção dos conteúdos. Assim, o processo de quadrinização rompe com esta construção fantasmagórica que passou a envolver as construções literárias, possibilitando, ao professor, atingir objetivos mais amplos em sua práxis. Neste sentido, segundo Vergueiro (2009),

A interligação do texto com a imagem, existente nas histórias em quadrinhos, amplia a compreensão de conceitos de uma forma que qualquer um dos códigos, isoladamente, teria dificuldades para atingir. $\mathrm{Na}$ medida em que essa interligação texto/imagem ocorre nos quadrinhos com uma dinâmica própria e complementar, representa muito mais do que o simples acréscimo de uma linguagem a outra como acontece, por exemplo, nos livros ilustrados -, mas a criação de um novo nível de comunicação [...] (VERGUEIRO, 2009, p. 22).

Vergueiro esclarece que a quadrinização de obras literárias clássicas cria um universo singular de entendimento da obra, porque assume uma nova postura e uma forma particular de ser e estar exposta ao leitor. Ressalta que ela assume uma posição própria, uma sintetização que é construída em conjunto por aqueles que elaboram a adaptação, compreendendo que não basta traduzir a linguagem vernácula clássica para uma linguagem mais próxima da realidade social em que se comporta a população das escolas públicas, há que ter todo um estudo, profundo e dinâmico, para que a essência do texto original mantenha-se presente e acessível quando da interpretação pelo estudante-leitor. Diferentemente disto, ter-se-ia uma construção 
arbitrária, visando atender à um nicho de mercado e não é a isto que se presta a elaboração de tal propositura com a adaptação quadrinística dos textos clássicos.

Pina (2014) faz uma observação profunda com relação à adaptação de textos literários clássicos para os quadrinhos, em que, segundo a autora, o leitor deve ser capacitado a sentir-se atravessado pela experiência do que irá ser adequado à sua construção intelectual, isto porque o texto original mantém-se vivo e preponderante na conjuntura mesmo da obra adaptada, esclarecendo que o roteirista realiza um processo dinâmico de intertextualidade e não supra textualidade ou transtextualidade, tomando o cuidado aqui de expor que, ao adaptar, o artista introjeta sua visão sobre o que é realizado e não pode-se perder de vista que haverá vieses os quais não podem interferir na estrutura intelectual da obra. Cabe, assim, ao professor, que seja preparado o suficiente para orientar as leituras e as análises até o limite de que o estudante saiba o que buscar e o porquê de fazê-lo ao longo dos seus estudos autônomos e em grupo.

Assim se expressa a autora supracitada com relação à adaptação de obras canônicas para os quadrinhos:

No processo de adaptação para os quadrinhos, ainda que a mídia seja a mesma da literatura, as linguagens interagem e o texto adaptante, mostrando-se em sua intertextualidade, convida o leitor a atravessar o lido, a interpretar e criar, a partir dos jogos textuais. O texto adaptado não é apagado, ele permanece no texto adaptante. Mas este não se submete àquele: são textos diferentes, um reconfigurado pelo outro, que não esconde essa marca, pelo contrário, se mostra exatamente como transcriação, transmutação (PINA, 2004, p. 159).

Esta colocação de Pina (2014) acende uma condição de alerta, porque exige que o professor esteja inteirado acerca da condição desta apropriação do texto original pelo adaptado, não estando sujeito a reduzir-se a ele como algo que possa explicar a formação de um leitor crítico, capaz de fazer conexões complexas a partir do pensamento original dos autores. Da mesma forma que ela explica em que há um processo que transcende a criação original, tendo como ponto de partida e de chegada a obra original, o professor deve ser capaz de entender que necessita criar estratégia de ensino para si mesmo e pensar em como seu estudante irá aprender o que lhe está sendo ofertado. Mesmo que se diga que há avanços nos processos de aprendizagem, 
fica-se na meia curva exponencial sobre o que fazer depois que foi proporcionado o gosto eclético pela leitura de literatura vernácula clássica e internacional nos estudantes. Santos (2015) argumenta que:

São desejáveis experiências didáticas que visem fortalecer essa possibilidade, resultando em benefícios para a área de literatura e de artes visuais; consequentemente, o educando será estimulado à leitura da linguagem literária clássica por meio de outra linguagem, a visual. Será possível perceber, em decorrência, a integração das duas linguagens na leitura e produção de literatura em quadrinhos (SANTOS, 2015, p. 5-6).

Como estratégia de ensino de literatura e incentivo na formação de leitores, Pina (2014) ressalta que, "os textos, quando associados às imagens, diminuem significativamente o tempo de estudo e, na maioria das vezes, promovem maior entendimento por meio da possibilidade de reunir muito mais informação em menor espaço, além de exemplos que gerariam páginas de descrição" (PINA, 2014, p. 2). Esta capacidade de proporcionar maior elasticidade a que a autora atribui aos quadrinhos pode ser devido ao formato de imagens que permite uma sobreposição de análises, linguagens e leituras dos processos de entendimento do que é posto como desafio ao estudante.

A leitura da imagem, às vezes, proporciona maior amplitude de capacidade de compreensão, tomando o devido cuidado para não cercear a capacidade crítica de interpretação crítica do estudante, ressalvando que, ao quadrinizar textos, não se pode transformar a atividade didática de ensino da literatura em redundância, reduzindo-a à uma mera atividade política ideológica, com intenções de inclusão de sujeitos marginalizados, em muitas das vezes, desinteressados de qualquer tipo de esforço intelectual-cognitivo. Isto faz surgir a necessidade premente de

Um projeto de leitura que envolva a associação entre o texto literário e sua recriação pela $\mathrm{HQ}$ pode se configurar como ação importante no estímulo à formação leitora de estudantes do Ensino Médio, o que evidentemente pode ser profícuo para todas as séries da Educação Básica. Isso porque a literatura transmutada para a história em quadrinhos pode ser uma grande provocação a crianças e jovens tão afeitos às visualidades, já que sujeitos de uma época em que as imagens prevalecem nos discursos mais acessados (SANTOS, 2015, p. 9). 
Pina (2014) é enfática ao defender esta postura e esclarece, a fim de dirimir quaisquer intervenções e interpretações de cunho pejorativo, que é "por meio da adaptação de um texto literário para as HQs, tem-se maior acessibilidade e compreensão de sua linguagem, auxiliando no processo de aproximação do indivíduo com a leitura e constitui uma estratégia eficaz de ensino para aplicação no ambiente escolar" (2014, p. 3). Há que destacar que quando se fala em estratégia de ensino, pensa-se à longo prazo, em que se têm objetivos de ensino, assimilação, acomodação, síntese e aprimoramento deste saber aplicando-o a outros setores do saber e na construção da personalidade leitora-interpretativa. Como isto será processado depende da ação educativa, didático-pedagógica, em que o professor pensa a ação docente seguinte à medida que seu estudante demonstra o aperfeiçoamento e a absorção dos conteúdos, que, deve-se salientar, não é original, tendo sofrido impactos daquele que o adaptou. Neste sentido, Pina volta a alertar para o fato de que,

$O$ ato da leitura de um texto resultante de um processo de adaptação, segundo entendo, demanda a encenação do próprio processo: ler uma adaptação quadrinística, por exemplo, feita a partir de um romance de Machado de Assis, demanda saber que o texto de chegada não é autônomo - ele demanda o estabelecimento de relações de sentido com o texto de partida (PINA, 2014, p. 152).

Pina (2014), chama a atenção, nesta epígrafe, para a formação do professor, no sentido da questão didática, em que a escolha de um texto deve obedecer a critérios de conhecimento profundo acerca do autor, de como pensava os aspectos sociológicos que envolvem a obra, toda a filosofia que marca o pensamento do mesmo, a psicologia do objeto analisado, estudado e seu próprio grau de entendimento e compreensão da obra a que se propõe apresentar aos estudantes. Vergueiro (2010), salienta que a literatura em quadrinhos é uma metodologia de ensino que deve ser pensada e estudada de modo a atingir fins claros e objetivos, exigindo, para tanto, estudos e performance, de acordo com a exigência dos objetosalvos. Assim: "os quadrinhos não podem ser vistos pela escola como uma espécie de panaceia que atende a todo e qualquer objetivo educacional" (VERGUEIRO, 2010, p. 27). 
O objetivo não é ensinar literatura, mas sim utilizar tal tática como um meio para se atingir um fim, que é o de despertar os estudantes para o gosto e a paixão pela literatura clássica, possibilitando uma condição mais favorável de entendimento do que foi exposto pelo autor no momento da confecção do texto original. Isto não dispensa todo um estudo sistemático em torno da obra e do autor. Para Barbosa et al (2006, pp. 24-25):

Não existe qualquer barreira para o aproveitamento das histórias em quadrinhos nos anos escolares iniciais e tampouco para sua utilização em séries mais avançadas mesmo em nível universitário. A grande variedade de títulos, temas e histórias existentes permite que qualquer professor possa identificar materiais apropriados para sua classe de alunos, sejam de qualquer nível ou faixa etária, seja qual for o assunto que deseje desenvolver com eles.

Ao colocar de modo enfático a condição para se ensinar literatura utilizando uma determinada metodologia que, apesar de ser nova, demanda tanto ou mais domínio por parte do professor quando comparada à forma tradicional de ensino, pode-se produzir a ideia de que os quadrinhos baixam o nível de intelectualidade/complexidade da obra, permitindo, ao leitor, seu entendimento completo, o que não condiz com a verdade, porque uma filosofia é uma filosofia, não importando a forma como está expressa e posta ao leitor, porque o veículo apenas transporta a realidade, não a adultera de modo substancial. Logo, todo um estudo acerca da psicologia do objetoalvo deve ser desenvolvido a fim de permitir aproximar-se ao máximo de uma categorização do ensino e da aprendizagem, caracterizando o processo didático em sua máxima potencialidade. Perrelli e Stryer (2012) reforçam a ideia de que,

As histórias em quadrinhos podem ser consideradas ferramentas importantes para se iniciar o processo de incentivo à leitura em sala de aula. Nesse sentido, o professor poderá, por meio desse gênero textual, trabalhar com a leitura de textos escritos acompanhados de textos visuais. Levar os alunos a perceberem que existem vários elementos que colaboram para a compreensão do texto, como por exemplo, os indicativos de deslocamentos, sons, espaços entre outros elementos presentes no texto. Muito importante será também fazer a diferenciação entre balões que indicam que a personagem está falando dos que indicam que a personagem está pensando, bem como fazer a exploração das expressões faciais dos personagens (PERRELLI; STRYER, 2012, p. 14). 
Os autores citados reforçam o aspecto didático que pode ser dado às histórias em quadrinhos, possibilitando fundir a semiótica, as diversas formas de linguagem, os princípios de absorção dos conteúdos postos e a distinção entre os diálogos. Trata-se de uma forma exponencial de ensino e de aprendizagem que exige formação elementar do professor e categorias de estudo por parte do estudante e, assim entendida, não se trata de baixar o nível dos textos ou dos estudantes; antes deve ser entendida e compreendida como uma técnica metodológica que pode proporcionar excelentes resultados nos campos semânticos do saber e do aprender, proporcionando a formação de habilidades e competências literárias, linguísticas e dialéticas.

\section{LITERATURA NO MUNDO E LITERATURA NO BRASIL}

A literatura sempre teve um papel muito definido ao longo da história humana, desde quando ainda se tinha como tradição a transmissão oral dos conhecimentos e dos feitos heroicos até chegar ao instante em que se desenvolve a imprensa e os livros, tornam-se, relativamente, acessíveis economicamente à uma parcela maior da sociedade. Se há aqueles que creem ser sua missão a desenvolver o entretenimento, esta é uma ideia quase equivocada pelo fato de não limitar-se a isto, estando muito mais vinculada à necessidade que se mostrava em dado momento histórico. A literatura, segundo Cândido:

Tem sido um instrumento poderoso de instrução e educação, entrando nos currículos, sendo proposta a cada um como equipamento intelectual e afetivo. Os valores que a sociedade preconiza, ou os que considera prejudicais, estão presentes nas diversas manifestações da ficção, da poesia e da ação dramática. A literatura confirma e nega, propõe e denuncia, apoia e combate, fornecendo a possibilidade de vivermos dialeticamente os problemas (CÂNDIDO, 1989, p. 113).

Esta tem se apresentado, portanto, como alude Cândido (1989) em seu estudo, como uma missão universal e quase uma forma de sobrevivência, porque tem de conviver com a existência paralela de outras formas de artes que se mostram mais atrativas, como o cinema, por exemplo, sobretudo no mundo atual em que vivemos, em que há certa desvalorização da literatura. Isto não quer dizer que a literatura esteja em perigo 
de morte, apenas que terminou por aderir a um discurso que, historicamente, não representa o escopo da mesma. É algo que decorre desde a aparição dos primeiros livros em que a intenção dos autores era a de apresentar um mundo idealizado, tendo como fundamento de sua produção, o espaço em que vivia e as inconstâncias que desafiavam a imaginação. Mas, de uma forma interessante, ela encontrou e também criou mecanismos de propagação dos ideais políticos, de denúncias das arbitrariedades das autoridades políticas, eclesiásticas e de grupos marginais que se diziam defensores das liberdades individuais.

Isto pode ser encontrado nas obras clássicas de Victor Hugo (1802-1885), León Tostói (1828-1910), Fiodór Dostoiévsky (1821-1881) e diversos outros autores clássicos da literatura universal que escreveram grandes obras de ficção que mascaravam uma realidade brutal, a qual não se mostrava à vista de todos, como o foi a obra de $\mathrm{A}$. Huxley (1894-1963), Admirável mundo novo (1932) e 1984 (1949) e A revolução dos Bichos (1945), ambas do escritor George Orwell (1903-1950). Aqui no Brasil a literatura não foi menos forte em tratar os problemas domésticos como menos importantes e talvez por este motivo, não tenha alcançado o brilho que teve outros autores de renome internacional, como os já citados. Mas, uma coisa é fato, a dimensão dos escritores que produziram obras clássicas no país mostra um retrato nítido de um momento histórico que foi e continua sendo negligenciado pela história oficial, cabendo, na atualidade, a oportunidade de que se possa resgatar o viés pedagógico e didático que cabe à esta expressão artística.

José Veríssimo escreveu, em 1912, que:

A Literatura que se escreve no Brasil é já a expressão de um pensamento e sentimento que se não confundem mais com o português, e em forma que, apesar da comunidade da língua, não é mais inteiramente portuguesa. $\hat{E}$ isto absolutamente certo desde o Romantismo, que foi a nossa emancipação literária, seguindo-se naturalmente à nossa independência política. Mas o sentimento que o promoveu e principalmente o distinguiu, o espírito nativista primeiro e o nacionalista depois, esse se veio formando desde as nossas primeiras manifestações literárias, sem que a vassalagem ao pensamento e ao espírito português lograsse jamais abafá-lo. É exatamente essa persistência no tempo e no espaço de tal sentimento, manifestado 
literariamente, que dá à nossa literatura a unidade e lhe justifica a autonomia (VERÍSSIMO, 1912, p. 4).

Esta é a principal característica que se pode pensar sobre a literatura no mundo e no Brasil, atualmente, marcada por uma expressiva ausência de escritores que traduzam os anseios do momento político para uma obra que possa expressar, de maneira condensada, o que sente o povo e não consegue expor, seja pela pressão do cotidiano, seja pela formação deficiente que se deu a partir da abertura de escolas de todos os pensamentos, permitindo nascer o ecletismo como um meio de adaptar-se à todos os gostos e tipos. Os grandes clássicos da literatura universal e brasileira são marcados pela construção de um cenário romântico sobre uma matriz histórica, técnica que, em todas as vezes que o Cinema buscou adaptar, o resultado foi o sucesso de crítica e de bilheteria, que se pode considerar a crítica mais pesada e que realmente interessa aos produtores/roteiristas, porque se trata da aceitação do público. Está é, portanto, segundo as reflexões e contribuições de Cândido, a função social e insubstituível da literatura.

Não é somenos citar aqui, o caso da obra de Margaret Mitchell (1900-1949), ...e o ventou levou (1936) que quando de seu lançamento, em plena recessão econômica norte-americana vendeu, somente na primeira semana, meio milhão de cópias, feito jamais superado pela literatura romântica, em qualquer outra época da história. Aqui no Brasil cita-se Castro Alves (1847-1871), Aluísio de Azevedo (1857-1913), autores que souberam explorar os campos histórico-sociais e sobre estas bases epistemológicas se consolidaram. Há Júlio Ribeiro (1845-1890), que explorou a questão dos instintos e do desejo humano inerente à sua existência. O que ocorre é que a literatura brasileira e a universal atravessam um instante de crise intelectual, em que se crê que textos sobre adolescentes bruxos e vampiros ou lobisomens platinados representam os problemas existenciais de um mundo que se transforma a uma velocidade alucinante, girando a tal pressão que volta e meia, alguns são jogados para fora da nave dos insensatos e os que persistem apenas lutam para não serem os próximos. 
Trata-se da era da literatura trash[6], em que nada de interessante é criado e aquilo que, por curtos instantes, pode encantar é descartável.

\section{HQ: UMA NOVA MODALIDADE DE LITERATURA?!}

Não se pode exagerar na crença de que as histórias em quadrinhos represente ainda uma modalidade de literatura, porque isto seria incorrer em um erro de considerar qualquer manifestação como sendo expressão literária digna de fazer parte do universo vernáculo erudito. Não se pode deixar levar pela ingenuidade de que depois de 08 (oito) décadas esta modalidade de expressão cultural não tenha se mostrado digna de receber um espaço mais amplo nos meios acadêmicos formais, participando de estudos e de processos formais de entendimentos sobre qual é seu público, como ele se comporta, como se apresenta e se o que Reblin (2016) diz sobre os quadrinhos se mostra factível por si só ou se realmente há uma tendência universal a aderir aos mesmos como uma nova modalidade literária.

O que faz a literatura de quadrinhos, na atualidade e desde a década de 1980, ganhar tamanha atenção de todos é o surgimento didático da interdisciplinaridade como um instrumental de trabalho pedagógico, que possibilitou e mesmo, para além de influenciar, obrigou a semiótica a unir-se à literatura, transformando a arte de quadrinização em uma ciência, dotando-a de técnicas muito mais sofisticadas, capazes de produzir e reproduzir o real. Agrega-se à isto a Linguística, a Epistemologia, a Eurística, a Psicologia e a Psiquiatria e com muito mais força a Psicanálise, ou seja, a literatura dos quadrinhos conseguiu absorver tudo o que de muito melhor e superior a literatura universal e os grandes escritores clássicos expressaram em seus versos e prosa. Xavier (2018) argumenta que,

Alguns pesquisadores consideram os quadrinhos uma forma de literatura. No entanto, Ramos (2010, p. 17) discorda ao dizer que chamar quadrinhos de literatura nada mais é do que "uma forma de procurar rótulos socialmente aceitos ou academicamente prestigiados", já que estes eram vistos historicamente de maneira pejorativa. Segundo o autor, "quadrinhos são quadrinhos", pois estes possuem linguagem autônoma, que usa mecanismos próprios para representar os elementos narrativos (XAVIER, 2018, p. 8). 
O que pode constatar desta epígrafe é que o autor citado faz uma alusão a que se tomar os quadrinhos como uma modalidade literária estar-se-ia colocando-os em um rol de classificação e isto é algo que poderia provocar o surgimento de interpretações e certo limite à produção dos roteiristas, como se fosse algo canônico, o que representaria uma perda para a produção como tal, porque, como cita Rubem Alves (2002), em terra de urubu diplomado, sabiá não canta, com isto entendendo que quem não segue os padrões estéticos, literários e canônicos determinados pelos críticos acadêmicos estaria fora do meio de produção. Quanto à epígrafe que abre este tópico, ela, por si só, traz um entendimento e uma ambiguidade, até mesmo pela dimensão da discussão que se desdobra sobre o tema proposto. Não se pode considerá-la como uma modalidade de literatura se se toma como ponto de análise as obras clássicas e nem se pode ignorar sua condição de modalidade literária se ela atende aos mesmos princípios que toda a literatura oficial, canônica.

\section{CONSIDERAÇÕES FINAIS}

Após os estudos realizados, bem com a partir das análises aplicadas e, também, com os resultados alcançados, chega-se à conclusão de que as histórias em quadrinhos conquistaram um espaço especial no imaginário da população, e, dessa forma, a sua introdução no contexto da sala de aula é de suma importância para conquistar novos leitores, começando pelos mais jovens, uma vez que seu público-alvo era, de início as crianças, devido ao aspecto de desenvolvimento linguístico e aprimoramento da língua, gosto pela leitura e conhecimento literários. Essa introdução prévia é essencial. A grande questão que se apresentou como leitmotiv desta dissertação é a de que se seria possível adaptar os clássicos da literatura clássica canônica vernácula brasileira utilizando os autores de maior renome do país neste campo. Para isto, buscou-se analisar, didaticamente, como se procederia até se chegar a tal ponto e quais os objetivos seriam traçados com a finalidade de se construir a produção léxica dos estudantes.

Partiu-se do entendimento de que a literatura é um bem necessário à economia psíquica de um indivíduo e, também, um componente didático valioso para a manutenção e a transmissão da história factual, pois sobre os escombros e as ruínas 
os autores constroem e edificam grandes clássicos, como foi citado ao longo do trabalho, desde Homero, na Grécia até Ovídio, na Itália, Tostói e Dostoiévsky, na Rússia, Margaret Mitchell, nos Estados Unidos da América, Milan Kundera, na Cortina de Ferro, Gorge Orwell que, enquanto escrevia seu romance 1984, estava sob vigilância austera da Scotlan Yard. Como desafios postos para futuras investigações, tem-se que a técnica de quadrinização necessita de investiduras mais profundas em suas concepções e estruturação didática, porque trabalha com agremiação de inúmeras outras ciências que, para o sucesso da atividade quando aplicada empiricamente, não só o professor deve ter ciência das mesmas, como domínio, como o estudante também deve ser inteirado de suas possibilidades e potencialidades.

Conclui-se que o ensino de literatura clássica utilizando as histórias em quadrinhos representa um avanço epistêmico e didático incomparável na história e a quadrinização, uma oportunidade ímpar para que os estudantes possam aproximarse ao máximo da produção intelectual autônoma.

\section{REFERÊNCIAS}

ALVES, R. Histórias de quem gosta de ensinar. Campinas: Papirus, 2002.

AMARILHA, M. Magali e Cascão vão à escola: transitando entre imagens e palavras. In: Alice que não foi ao país das maravilhas: a leitura crítica na sala de aula. Petrópolis: Vozes, 2006.

BARBOSA, A. et al. Como usar as histórias em quadrinhos na sala de aula. $3^{\underline{a}} \mathrm{ed}$. São Paulo: Contexto, 2006.

CANDIDO, A. Direitos Humanos e literatura. In: FESTER, A.C.R. (Org.) Direitos humanos. São Paulo: Brasiliense, 1989.

DALCASTAGNÈ, R. (Org.). Histórias em quadrinhos: diante da experiência dos outros. São Paulo, Editora Horizonte, 2012. 
FREIRE, P. Pedagogia da Autonomia: saberes necessários à prática educativa. $2^{\mathrm{a}}$ ed. Rio de Janeiro: Paz e Terra, 1997.

LIMA, M. S. de. Literatura em Quadrinhos: Uma questão de adaptação. In: XIV Congresso de Ciências da Comunicação na Região Nordeste, 2012.

LINS, M. da. P. P. O tópico discursivo em textos de quadrinhos. Vitória: EDUFES, 2008.

OLIVEIRA, M. C. X. de. A Arte dos "Quadrinhos" e o Literário: a contribuição do diálogo entre o Verbal e o Visual para a reprodução e inovação dos modelos clássicos da cultura. 2008. 207f. Tese (Doutorado em Estudos Comparados de Literaturas de Língua Portuguesa). Universidade Estadual de São Paulo (USP), São Paulo, 2008.

PERRELLI, M. R.; STRYER, F. A. Leitura: a contribuição das histórias em quadrinhos para a formação do leitor. 2012. Disponível em: http://www.diaadiaeducacao.pr.gov.br/portals/cadernospde/pdebusca/producoes_pd e/2012/2012_uepg_port_artigo_marcia_regina_perrelli_dudziak.pdf. Acesso em: 22 set. 2016.

PINA, P. K. da. C. Literatura e quadrinhos em diálogo: Adaptação e leitura hoje. Ipotesi, v.18, n. 2, p. 149-164, jul./dez. 2014.

REBLIN, I. A. Quadrinhos nas aulas de Ensino Religioso: subsídios e práticas pedagógicas de uma experiência docente. Estudos Teológicos (On line), v. 56, p. 12-39, 2016.

SANTOS, W. A. dos. Literatura e história em quadrinhos na educação básica: uma sequência didática criativa. 2015. Disponível em: http://docplayer.com.br/70193181 Literatura-e-historia-em-quadrinhos-na-educacao-basica-uma-sequencia-didaticacriativa.html. Acesso em: 22 jul. 2020. 
VERGUEIRO, W. Quadrinhos e Educação Popular no Brasil. In: VERGUEIRO, W.; RAMOS, P. (Org.). Muito além dos quadrinhos: análises e reflexões sobre a 9a arte. São Paulo: Contexto, 2009.

VERGUEIRO, W.. Uso das HQs no ensino In: RAMA, A.; VERGUEIRO, W. (Org.). Como usar as histórias em quadrinhos na sala de aula. São Paulo: Contexto, 2010. VERÍSSIMO, J. História da literatura brasileira. Brasília: Ministério da Cultura; Rio de Janeiro: Fundação Biblioteca Nacional/Departamento Nacional do Livro, 1912.

XAVIER, G. K. R. da. S. Histórias em quadrinhos: panorama histórico, características e verbo-visualidade. Darandina Revista Eletrônica, v. 10, n. 2, p. 01-20, 2018.

\section{APÊNDICE - REFERÊNCIAS DE NOTA DE RODAPÉ}

3. Obra literária publicada, originalmente, em 1847.

4. O poema Mosca Azul, de Machado de Assis, publicado no livro Ocidentais [talvez em 1880] conta a história de um plebeu que, ao deparar-se com uma curiosa mosca azul, com asas de ouro e granada, deslumbra-se e passa a sonhar com poder e riquezas, ilusão que acaba comprometendo sua sanidade e seu senso de realidade.

5. Canônico é um adjetivo que caracteriza aquilo que está de acordo com os cânones, com as normas estabelecidas ou convencionadas.

6. A cultura popular que nos cerca em nossa vida cotidiana tem uma semelhança impressionante com algumas das grandes obras da literatura do passado. $\mathrm{Na}$ televisão, filmes, revistas e anúncios, estamos expostos a muitas das mesmas histórias que aqueles críticos que estudam os grandes livros da literatura ocidental, mas fomos simplesmente encorajados a olhar para essas histórias de maneira diferente. A grande literatura e o trabalho cultural do passado foram reescritos para a sociedade de consumo de hoje, com tablóides de supermercados como o National Enquirer e revistas de fofocas de celebridades como People, servindo como versões contemporâneas das grandes tragédias dramáticas do passado. A publicidade de hoje 
repete o conto da Idade de Ouro, mas inverte o sistema de valores de uma utopia clássica. ARTMELL, Deborah (1997). Estética do lixo: cultura popular e seu público: a cura de Deborah Cartmell. Plutão $\operatorname{Pr}(10$ de março de 1997). Pluto Pr.

Enviado: Junho, 2020.

Aprovado: Julho, 2020. 